\title{
Author Correction: Nanometre- scale pattern formation on the surface of a photochromic crystal by optical near-field induced photoisomerization
}

\author{
Ryo Nakagomi ${ }^{1}$, Kazuharu Uchiyama ${ }^{1}$, Hirotsugu Suzui ${ }^{1}$, Eri Hatano ${ }^{2}$, Kingo Uchida $^{2}$, \\ Makoto Naruse $^{3}$ \& Hirokazu Hori ${ }^{1}$
}

Correction to: Scientific Reports https://doi.org/10.1038/s41598-018-32862-9, published online 27 September 2018

In Figure 3C, the horizontal axis is incorrectly labelled as 'Position $(\mu \mathrm{m})$ '. This should read 'Position (nm)'. The correct Figure 3C appears below as Figure 1.

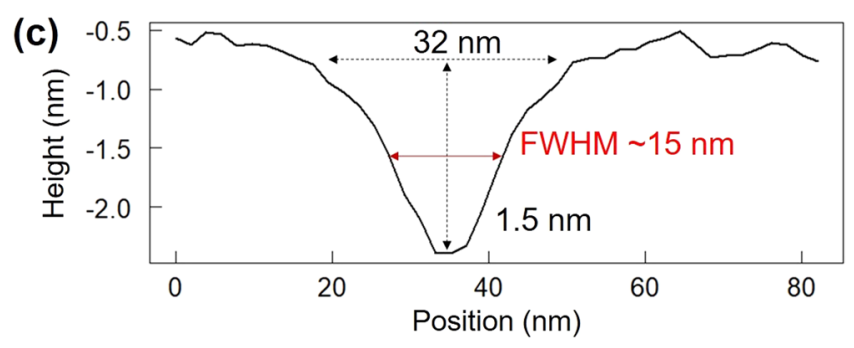

Figure 1. Local photoisomerization in a slightly coloured photochromic crystal. (c) Line profile obtained along the white line in (b).

(i) Open Access This article is licensed under a Creative Commons Attribution 4.0 International cc. License, which permits use, sharing, adaptation, distribution and reproduction in any medium or format, as long as you give appropriate credit to the original author(s) and the source, provide a link to the Creative Commons license, and indicate if changes were made. The images or other third party material in this article are included in the article's Creative Commons license, unless indicated otherwise in a credit line to the material. If material is not included in the article's Creative Commons license and your intended use is not permitted by statutory regulation or exceeds the permitted use, you will need to obtain permission directly from the copyright holder. To view a copy of this license, visit http://creativecommons.org/licenses/by/4.0/.

(C) The Author(s) 2018

${ }^{1}$ University of Yamanashi, 4-3-11 Takeda, Kofu, Yamanashi, 400-8511, Japan. ${ }^{2}$ Ryukoku University, 1-5 Yokotani, Oe-cho, Seta, Otsu, Shiga, 520-2194, Japan. ${ }^{3}$ Network System Research Institute, National Institute of Information and Communications Technology, 4-2-1 Nukui-kita, Koganei, Tokyo, 184-8795, Japan. Correspondence and requests for materials should be addressed to R.N. (email: rnakagomi1990@gmail.com) 